International Journal of Biology, Pharmacy and Allied Seiences (IJBPAS) 'A Bridge Betuen Caboratory and Qnendo'

WWw.ijbpas.com

\title{
EFFECTS OF PIEZO - CATALYSIS FOR TOOTH WHITENING - A REVIEW
}

\section{APURVA CHOUDHARY ${ }^{1}$, BALAJI GANESH $\mathrm{S}^{2^{*}}$ AND SMILINE GIRIJA A $\mathrm{S}^{3}$}

1: Research Associate, Saveetha Dental College, Saveetha Institute of Medical and Technical Science, Saveetha University, Chennai.

2: Scientist, White Lab- Materials Research Centre, Saveetha Dental College, Saveetha Institute of Medical and Technical Science, Saveetha University, Chennai 77

3: Associate Professor, Department of Microbiology, Saveetha Dental College, Saveetha Institute of Medical and Technical Science, Saveetha University, Chennai 77

*Corresponding Author: E Mail: Dr. Balaji Ganesh S: balajiganeshs.sdc@saveetha.com

Received 19 $9^{\text {th }}$ March 2021; Revised 20 ${ }^{\text {th }}$ April. 2021; Accepted $19^{\text {th }}$ May 2021; Available online $1^{\text {st }}$ Aug. 2021

https://doi.org/10.31032/IJBPAS/2021/10.8.1018

\begin{abstract}
The increasing demand for a whiter smile has resulted in an increased popularity for tooth whitening procedures. Fastest growing aesthetic dentistry procedure is tooth whitening. This review demonstrates that the piezo catalysis based on tooth whitening via BTO (Barium titanate) nanoparticles is non destructive to the tooth enamel and biocompatible without cytotoxicity as compared to other clinical whitening agents. This review demonstrates that the piezo -catalysis based tooth whitening via BTO nanoparticles is non destructive to the tooth enamel and biocompatible without cytotoxicity as compared to other clinical whitening agents. Piezocatalysis tooth whitening has the ability to be widely adopted for home use, without requiring significant investment. It can also be used in clinical aspects. The review article concludes that piezo - catalysis effects based tooth whitening method can replace traditional abrasive in the toothpaste and to generate reactive oxygen species via piezo - catalysis to bleach tooth stains.
\end{abstract}

Keywords: Piezo catalysis; Tooth whitening; Nanoparticles 


\section{INTRODUCTION}

People are eager to improve their appearance with a whiter smile with the development of the aesthetic standard. Fastest growing aesthetic dentistry procedure is tooth whitening [1]. Due to the various factors such as tobacco use, drug ingestion, eating dark fruits, consumption of vinegars causes discolouration and staining of teeth [2]. One study demonstrated that tooth stain can be whitened after root canal [3] and cleaning and shaping [4]. There are several common methods for tooth whitening, such as professional cleaning and polishing, coverage with crowns or veneers, daily tooth brushing with the help of abrasive toothpaste and bleaching [5]. These all techniques are expensive and time consuming [6]. Lightening tooth color can be done by a wide variety of bleaching methods, including inoffice (professionally administered), at-home (professionally dispensed) and over-thecounter (self-administered) techniques. Home bleaching techniques require more procedural time and cannot be well controlled due to their mode of administration. The main advantages of inoffice bleaching technique includes dentist control, avoidance of tissue exposure, reduced treatment time and enhanced patient satisfaction due to immediate results. Since
1910, Power bleaching has been performed using varying hydrogen peroxide activation techniques [7]. Serious concerns have been stated concerning the safety of conventional hydrogen peroxide- containing bleaching products, including enamel surface alterations including minute depressions, porosities and slight erosive defects following scanning electron microscopic evaluations. Considering the fact that $\mathrm{pH}$ of different brands of bleaching gels vary greatly, it is stated that in a laboratory setting hydrogen peroxide solution $(\mathrm{pH}=6.4)$ is able to remove mineral contents of enamel, although the critical $\mathrm{pH}$ for enamel demineralization has been considered to be between 5.2 and 5.8 [8]. Laser-assisted bleaching uses laser beams to accelerate release of free radicals within the bleaching gel to decrease time of whitening procedure. Lasing is also capable of minimizing postbleaching hypersensitivity, loss of enamel microhardness and gingival irritation due to lack of hydrogen peroxide use. Decreased chair time can also be anticipated following laser use. Many authors have indicated that light energy does not have any clinical influence on tooth whitening [9]. Calcium phosphate with bioactive glass can be used in tooth bleaching [10] and GIC barrier in non 
vital tooth bleaching [11]. Bleaching options are there for calcified canal [12]. Bleaching agents may increase the matrix metalloproteinases mediated collagen degradation in dentin [13]. Bleaching can have some effects in pulp vitality [14]. Veneers are one of the esthetics options available [15]. There are various different treatments in tooth whitening [16]. And dental practitioners are aware of that [17].

One study demonstrated that the piezoelectric effect is the electric charge that accumulates in solid materials and responses to the mechanical stress [18]. Piezoelectric materials are ultra sensitive to mechanical vibration, water flow, muscle movement and can induce electric changes [19]. Since it has the ability to convert mechanical stimuli into electrical signals. Piezoelectric materials can be used as catalysers, which can be called piezo catalysis or melchano- catalysis [20]. Classical piezoelectric materials such as $\mathrm{ZnO}, \mathrm{BaTiO} 3$ and $\mathrm{BiFeO} 3$ can be demonstrated as efficient piezo- catalysis [21]. The effects of piezo -catalysis is similar to photo catalysis, it is based on photo induced charges rather than mechanically induced charges. The aim of review is to analyse the effects of piezo -catalysis for tooth whitening.

\section{Tooth whitening}

Tooth whitening is a form of treatment and it is a part of a comprehensive treatment plan, tooth whitening methods are safe and effective [22]. Tooth whitening methods include the use of abrasive products to remove external stains. The mineral phase of human teeth consists of calcium phosphate in the form of hydroxyapatite [23]. The original colour of pure hydroxyapatite is colourless white. Naturally enamel has white colour with some translucency. Due to continuous chemical and mechanical factors, enamel will become thinner and translucent due to that dentin will become more visible and the overall tooth colour will become darker [24]. The most classic hydrogen peroxide- based whitening agents are effective, but this can lead to enamel demineralisation, cytotoxicity. Piezo- catalysis techniques are harmless and convenient tooth whitening strategy by replacement by abrasives traditionally used in toothpaste with piezoelectric particles. Since electrical charges can be induced by mechanical vibration, piezoelectric materials have also been employed as catalysers, termed as piezo-catalysis or mechanocatalysis.

The piezoelectric effect, discovered in 1880 by brothers Pierre Curie and Jacques Curie, is the electric charge that accumulates in 
certain solid materials with non- based toothpaste method, where tooth centrosymmetric structure in response to whitening is realized by the mechanical mechanical stress. With the ability to convert mechanical stimuli into electrical signals, or vice versa, piezoelectric materials have been widely used for sensors, transducers, actuators, and energy harvesters for selfpowered devices. Some piezoelectric materials such as $\mathrm{ZnO}$, BaTiO3 are efficient piezo catalysts and can be used in daily toothbrush, a nondestructive and safe tooth whitening strategy based on the piezocatalysis effect, easily realized by replacement of abrasives with piezoelectric nano-particles. One study demonstrated the chlorhexidine causes staining of teeth [25, 26] and natural extract can also be used in future and can be used to remove the tooth stain [27]. Discoloration of teeth is one of the problems in cases of avulsion [28].

\section{Working principle}

When toothbrush and teeth come in contact during tooth brushing, there will be mechanical vibration between them as shown in Figure (1a). The traditional abrasivefriction between teeth and abrasive Figure (1b). There will be proposed piezo -catalysis effect based tooth whitening method wherein piezoelectric particles replace traditional abrasive in the toothpaste, to generate reactive oxygen species via piezo- catalysis to bleach tooth stains in Figure (1c). There will be original electrostatic poled piezoelectric materials in Figure (1d), the release of screening charges under compressive stress, which combine with water molecules and then produce reactive species in Figure (1e). This will cause modified electrostatic balance states under maximum compressive stress in Figure (1f). At last in Figure (1g), there will be adsorption of charges from the surrounding electrolyte under reduced compressive stress [29]. The charges in the electrolyte with opposite popularity to the adsorbed charges will participate in the redox reaction to produce reactive species [30]. This will cause the removal of the removal of stain. 
a.

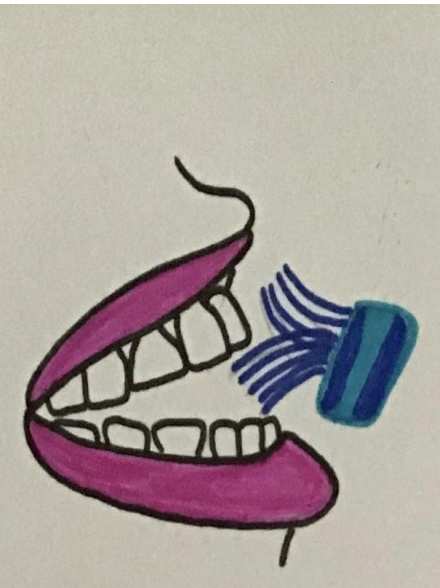

b.

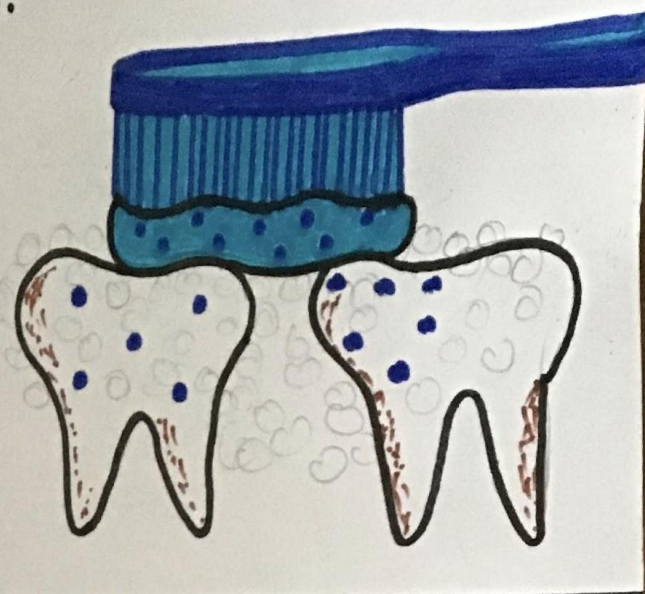

C.
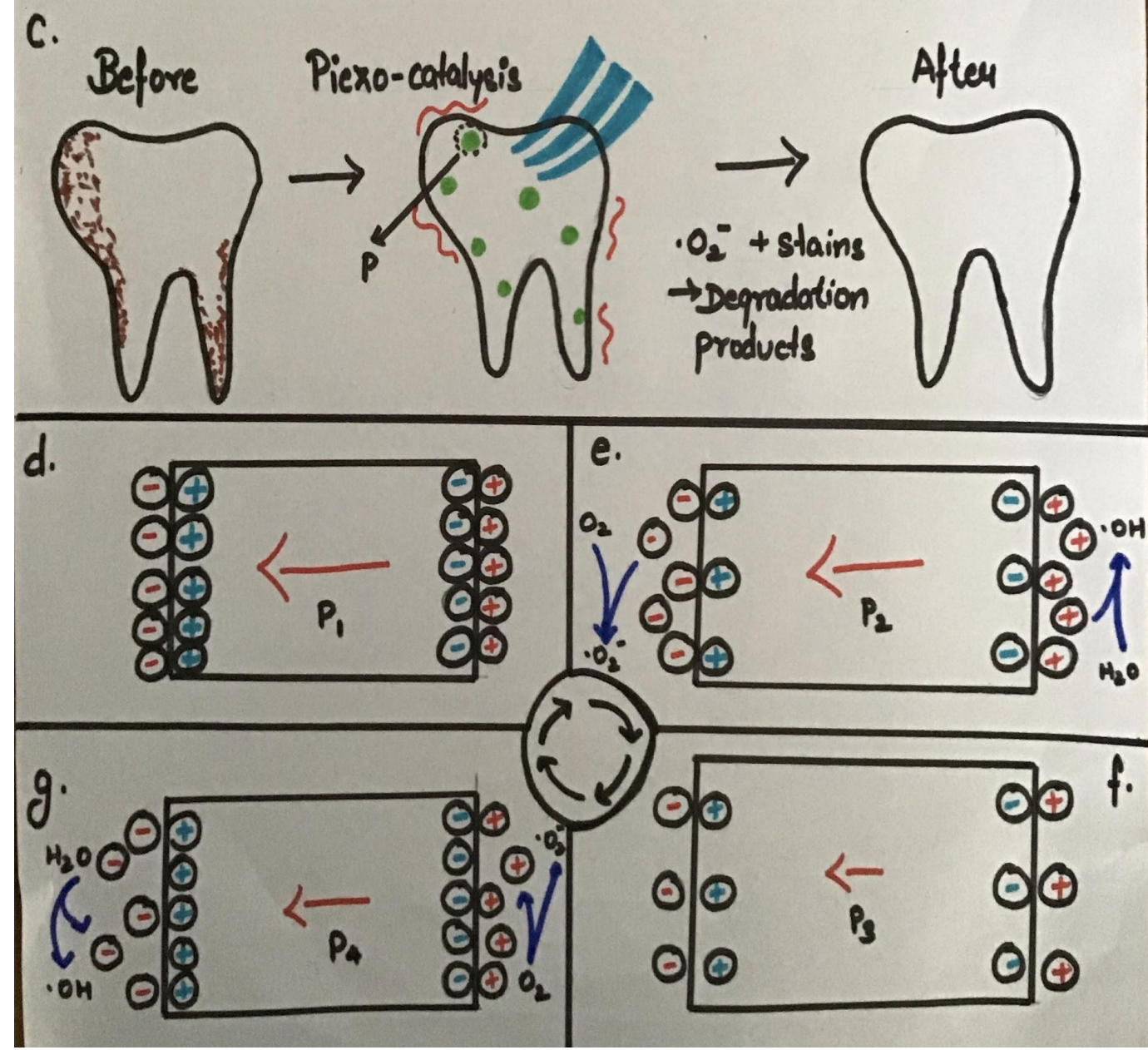

Figure 1: Working Principle of Tooth Whitening 


\section{Tooth whitening based on piezo - catalysis}

Previous article described about tooth whitening using poled BTO nanoparticles [31]. It is noted that the tooth whitening effect under constant vibration was more than that under discontinuous vibration. The concentration of BTO nanoparticles will decrease in the discontinuous vibration process. Piezo- catalysis based tooth whitening has been demonstrated using both ultrasonic excitation and with more traditional, commercial electric toothbrush. As such, this technique can accelerate the tooth whitening relative to the traditional mechanical friction of abrasive based toothpastes alone.

The reactive species produced by BTO nanoparticles oxidise the multiple conjugated double bonding of large organic molecules and convert into smaller compounds that is tooth whitening [32].

\section{Degradation based on piezo -catalysis}

Indigo carmine can be degraded by piezo catalysis. Indigo Carmine is a common good colorant used in juice drinks, carbonated beverages, and plays a key role in tooth staining [33]. The ultrasonic vibration was used to stimulate the mechanical stimuli during regular tooth brushing. It is evaluated that the piezo- catalysis performance of BTO nanoparticles can degrade the Indigo Carmine in aqueous solutions. The degradation of Indigo carmine via pole and unpole nanoparticles can be identified by its wavelength, vibration time and magnetic field.

The structural stability of nano- sized BTO also serves as the degradation of organic dye. The piezoelectricity dependence of degradation of organic dyes can also be understood by a series of chemical reactions.

$$
\begin{gathered}
\text { Piezo -particles + vibration -> Piezo- particles }\left(q^{-}+q^{+}\right) \\
q^{-}+O_{2}-. O_{2}^{-} \\
q^{+}+H_{2} O-. O H \\
O_{2}^{-}+\text {Organic dye }- \text { Degradation products }
\end{gathered}
$$

Non destructive and harmless nature of piezo - catalysis

Piezo catalysis based tooth whitening is non destructive to enamel. The biocompatibility of piezo catalysis was evaluated using the MTT method [34]. The BTO nanoparticles were confirmed as biocompatible, since the 
cells showed no charges with time and there is no difference relative to the control.

The cytotoxicity demonstrates the BTO nanoparticles are biologically safe and piezocatalytic tooth whitening procedure is harmless [35]. Additionally the possibility of leakage during vibration was also examined, and the results show no nanoparticle leakage during daily tooth brushing vibration levels.

It has been demonstrated that a nondestructive, biocompatible, costeffective, and time efficient tooth whitening strategy based on piezo- catalysis effect due to piezoelectric nanoparticles. The tooth whitening system shows excellent chemical, structural and electrical stability using pole BTO nanoparticles [36]. The piezo- catalysis based tooth whitening effect was also demonstrated using a more practical electric toothbrush and BTO turbid liquid $[37,38]$. This review demonstrates that the piezo catalysis based tooth whitening via BTO nanoparticles is non destructive to the tooth enamel and biocompatible without cytotoxicity as compared to other clinical whitening agents. Piezo- catalysis tooth whitening has the ability to be widely adopted for home use, without requiring significant investment. It can also be used in clinical aspects.

\section{CONCLUSION}

The review article concludes that piezocatalysis effect based tooth whitening method can replace traditional abrasive in the toothpaste and to generate reactive oxygen species via piezo - catalysis to bleach tooth stains.

\section{REFERENCES}

[1] Alqahtani MQ. Tooth-bleaching procedures and their controversial effects: A literature review. Saudi Dent J. 2014 Apr;26(2):33-46.

[2] Colares VLP, Lima SNL, Sousa NCF, Araújo MC, Pereira DMS, Mendes SJF, et al. Hydrogen peroxide-based products alter inflammatory and tissue damage-related proteins in the gingival crevicular fluid of healthy volunteers: a randomized trial. Sci Rep. 2019 Mar 5;9(1):3457.

[3] Ramamoorthi S, Nivedhitha MS, Divyanand MJ. Comparative evaluation of postoperative pain after using endodontic needle and EndoActivator during root canal irrigation: A randomised controlled trial. Aust Endod J. 2015 Aug;41(2):78-87.

[4] Teja KV, Ramesh S. Shape optimal and clean more. Saudi Endodontic Journal. 2019 Sep 1;9(3):235. 
[5] Soeteman GD, Valkenburg C, Van der Weijden GA, Van Loveren C, Bakker EWP, Slot DE. Whitening dentifrice and tooth surface discoloration-a systematic review and meta-analysis [Internet]. Vol. 16, International Journal of Dental Hygiene. 2018. p. 24-35. Available from:

http://dx.doi.org/10.1111/idh.12289

[6] Ontiveros JC, Paravina RD. In-Office Power Bleaching [Internet]. Tooth Whitening Techniques. 2017. p. 123 42. Available

from: http://dx.doi.org/10.1201/9781315365 503-7

[7] Artini DD, Effendy R. Efficacy of InOffice Tooth Bleaching Treatment Using Light Activated Hydrogen Peroxide Agent: A Case Report [Internet]. Proceedings of the 7th International Meeting and the 4th Joint Scientific Meeting in Dentistry. 2017. Available from: http://dx.doi.org/10.5220/0007292200 670071

[8] Driessens FCM, Theuns HM, J M P, van Dijk JWE. Solubility Behaviour of Whole Human Enamel [Internet]. Vol. 20, Caries Research. 1986. p. 103-10. Available from: http://dx.doi.org/10.1159/000260928

[9] Hein DK, Ploeger BJ, Hartup JK, Wagstaff RS, Palmer TM, Hansen LD. In-office vital tooth bleaching-what do lights add? Compend Contin Educ Dent. 2003 Apr;24(4A):340-52.

[10] Rajendran R, Kunjusankaran RN, Sandhya R, Anilkumar A, Santhosh R, Patil SR. Comparative Evaluation of Remineralizing Potential of a Paste Containing Bioactive Glass and a Topical Cream Containing Casein Phosphopeptide-Amorphous Calcium Phosphate: An in Vitro Study [Internet]. Vol. 19, Pesquisa Brasileira em Odontopediatria e Clínica Integrada. 2019. p. 1-10. Available from: http://dx.doi.org/10.4034/pboci.201 9.191.61

[11] Hussainy SN, Nasim I, Thomas T, Ranjan M. Clinical performance of resin-modified glass ionomer cement, flowable composite, and polyacid-modified resin composite in noncarious cervical lesions: Oneyear follow-up. J Conserv Dent. 2018 Sep;21(5):510-5.

[12] Kumar D, Delphine Priscilla Antony S. Calcified Canal and NegotiationA Review [Internet]. Vol. 11, 
Research Journal of Pharmacy and

Technology. 2018. p. 3727.

Available

from:

http://dx.doi.org/10.5958/0974-

360x.2018.00683.2

[13] Ramesh S, Teja K, Priya V. Regulation of matrix metalloproteinase-3 gene expression in inflammation: A molecular study [Internet]. Vol. 21, Journal of Conservative Dentistry. 2018. p. 592. Available from: http://dx.doi.org/10.4103/jcd.jcd_15 4_18

[14] Janani K, Palanivelu A, Sandhya R. Diagnostic accuracy of dental pulse oximeter with customized sensor holder, thermal test and electric pulp test for the evaluation of pulp vitality - An in vivo study [Internet]. Vol. 23, Brazilian Dental Science. 2020. Available from: http://dx.doi.org/10.14295/bds.2020. v23i1.1805

[15] Ravinthar K, Jayalakshmi. Recent Advancements in Laminates and Veneers in Dentistry [Internet]. Vol. 11, Research Journal of Pharmacy and Technology. 2018. p. 785. Available from:

http://dx.doi.org/10.5958/0974- 360x.2018.00148.8

[16] Jose J, P. A, Subbaiyan H. Different Treatment Modalities followed by Dental Practitioners for Ellis Class 2 Fracture - A Questionnaire-based Survey [Internet]. Vol. 14, The Open Dentistry Journal. 2020. p. 59-65. Available from: http://dx.doi.org/10.2174/18742106 02014010059

[17] Manohar M, Sharma S. A survey of the knowledge, attitude, and awareness about the principal choice of intracanal medicaments among the general dental practitioners and nonendodontic specialists [Internet]. Vol. 29, Indian Journal of Dental Research. 2018. p. 716. Available from:

http://dx.doi.org/10.4103/ijdr.ijdr_7 16_16

[18] Curie J, Curie P. Développement par compression de l'électricité polaire dans les cristaux hémièdres à faces inclinées [Internet]. Vol. 3, Bulletin de la Société minéralogique de France. 1880. p. 90-3. Available from: http://dx.doi.org/10.3406/bulmi.188 0.1564

[19] Feng Y, Li H, Ling L, Yan S, Pan 
$\mathrm{D}, \mathrm{Ge} \mathrm{H}$, et al. Enhanced Photocatalytic Degradation Performance by Fluid-Induced Piezoelectric Field [Internet]. Vol. 52, Environmental Science \& Technology. 2018. p. 7842-8. Available from: http://dx.doi.org/10.1021/acs.est.8b0 0946

[20] Wang X, Rohrer GS, Li H. Piezotronic modulations in electroand photochemical catalysis [Internet]. Vol. 43, MRS Bulletin. 2018. p. 946-51. Available from: http://dx.doi.org/10.1557/mrs.2018. 264

[21] Hong D, Zang W, Guo X, Fu Y, He $\mathrm{H}$, Sun $\mathrm{J}$, et al. High Piezophotocatalytic Efficiency of $\mathrm{CuS} / \mathrm{ZnO}$ Nanowires Using Both Solar and Mechanical Energy for Degrading Organic Dye [Internet]. Vol. 8, ACS Applied Materials \& Interfaces. 2016. p. 21302-14. Available from: http://dx.doi.org/10.1021/acsami.6b 05252

[22] Special Issue Introduction [Internet]. Vol. 11, Derrida Today. 2018. p. 133-133. Available from: http://dx.doi.org/10.3366/drt.2018.0
182

[23] Dorozhkin SV, Epple M. Biological and Medical Significance of Calcium Phosphates [Internet]. Vol. 41, Angewandte Chemie International Edition. 2002. p. 3130-46. Available from: http://dx.doi.org/10.1002/15213773(20020902)41:17<3130::aidanie3130>3.0.co;2-1

[24] Algarni AA, Ungar PS, Lippert F, Martínez-Mier EA, Eckert GJ, González-Cabezas C, et al. Trendanalysis of dental hard-tissue conditions as function of tooth age. $\mathrm{J}$ Dent. 2018 Jul;74:107-12.

[25] Siddique R, Sureshbabu NM, Somasundaram J, Jacob B, Selvam D. Qualitative and quantitative analysis of precipitate formation following interaction of chlorhexidine with sodium hypochlorite, neem, and tulsi. J Conserv Dent. 2019 Jan;22(1):40-7. [26] Noor SSSE, S Syed Shihaab, Pradeep. Chlorhexidine: Its properties and effects [Internet]. Vol. 9, Research Journal of Pharmacy and Technology. 2016. p. 1755. Available from: http://dx.doi.org/10.5958/0974- 
360x.2016.00353.x

[27] Nasim I, Nandakumar M. Comparative evaluation of grape seed and cranberry extracts in preventing enamel erosion: An optical emission spectrometric analysis [Internet]. Vol. 21, Journal of Conservative Dentistry. 2018. p. 516. Available from: http://dx.doi.org/10.4103/jcd.jcd_11 0_18

[28] R R, Rajakeerthi R, Ms N. Natural Product as the Storage medium for an avulsed tooth - A Systematic Review [Internet]. Vol. 22, Cumhuriyet Dental Journal. 2019. p. 249-56. Available from: http://dx.doi.org/10.7126/cumudj.52 5182

[29] Copie O, Chevalier N, Le Rhun G, Rountree CL, Martinotti D, Gonzalez S, et al. Adsorbate Screening of Surface Charge of Microscopic Ferroelectric Domains in Sol-Gel PbZr0.2Ti0.8O3 Thin Films [Internet]. Vol. 9, ACS Applied Materials \& Interfaces. 2017. p. 29311-7. Available from: http://dx.doi.org/10.1021/acsami.7b 08925

[30] Chen X, Li Y, Pan X, Cortie D,
Huang X, Yi Z. Photocatalytic oxidation of methane over silver decorated zinc oxide nanocatalysts [Internet]. Vol. 7, Nature Communications. 2016. Available from:

http://dx.doi.org/10.1038/ncomms12 273

[31] Wang Y, Wen X, Jia Y, Huang M, Wang F, Zhang $\mathrm{X}$, et al. Piezocatalysis for nondestructive tooth whitening. Nat Commun. 2020 Mar 12;11(1):1328.

[32] Greenwall L. Tooth Whitening Techniques. CRC Press; 2017. 352 p.

[33] Jesionowski T, Ciesielczyk F. Multifunctional Oxide-Based Materials: From Synthesis to Application. MDPI; 2019. 202 p.

[34] Deng A, Yang Y, Du S, Yang S. Electrospinning of in situ crosslinked recombinant human collagen peptide/chitosan nanofibers for wound healing [Internet]. Vol. 6, Biomaterials Science. 2018. p. 2197-208. Available from: http://dx.doi.org/10.1039/c8bm0049 $2 \mathrm{~g}$

[35] Kawamoto K, Tsujimoto Y. Effects of the Hydroxyl Radical and 
Hydrogen Peroxide on Tooth

Bleaching [Internet]. Vol. 30,

Journal of Endodontics. 2004. p.

45-50. Available from:

http://dx.doi.org/10.1097/00004770-

200401000-00010

[36] Ye Z-G. Handbook of Advanced Dielectric, Piezoelectric and Ferroelectric Materials: Synthesis, Properties and Applications. Elsevier; 2008. 1096 p.

[37] Ma X, Li R, Sa Y, Liang S, Sun L, Jiang T, et al. Separate contribution of enamel and dentine to overall tooth colour change in tooth bleaching [Internet]. Vol. 39, Journal of Dentistry. 2011. p. 73945. Available from: http://dx.doi.org/10.1016/j.jdent.201 1.08 .005

[38] Ramanathan S, Solete P. Cone-beam Computed Tomography Evaluation of Root Canal Preparation using Various Rotary Instruments: An in vitro Study [Internet]. Vol. 16, The Journal of Contemporary Dental Practice. 2015. p. 869-72. Available from: http://dx.doi.org/10.5005/jpjournals-10024-1773 